\title{
Viral crossings
}

A try markets in several Asian countries and has crossed into the human population. According to WHO reports, as of February 23, 2004, there was a total of 32 human cases, 22 resulting in death (this includes only laboratory-confirmed cases). The high death rate but relatively low number of cases indicates two things: this virus can be very deadly to a new host, but it is slow to spread between individuals.

A virus that has found a way to propagate within a new host is difficult to combat because the immune system has never seen anything like it before and cannot mount a proper response - until it is too late.

Researchers once believed that avian influenza must first pass through another host, such as the pig, before being able to move into humans. In 1997, in Hong Kong, the first case of an avian virus going directly from a bird to a human was recorded, and our perceptions of the dangers and realities of such crossings were forever altered.

Yoshihiro Kawaoka, of the University of Wisconsin and the University of Tokyo, told the JCI that it is still uncertain how common direct transfer from birds to humans is.

"There are two possibilities," says Kawaoka. "There are some new [avian viruses] that are able to be transmitted at a low level, unlike viruses we have previously known." Alternatively, "the surveillance [of viruses] may be more extensive and sophisticated than before."

Kawaoka explained that "surveillance [of viruses worldwide] is quite different now. Since the 1990s, the surveillance system has evolved into a comprehensive network; we are able to detect even minor transmissions among different animal species." So, with our current detection levels, what was once thought to be rare may in fact be relatively common.

In the current viral surveillance system, says Kawaoka, a network of laboratories worldwide "go through human isolates from infected individuals. If the virus is at all different [from known samples], they send it to the CDC and other centers. [These centers] then check to see if these are human viruses or something different."

The dangers for the human population of a virus that is "something different" were

never more evident than in the influenza pandemic of 1918 that killed over 600,000 people in the US and 40 million worldwide.

Two recent reports $(1,2)$ on the $x$-ray crystallographic structure of the hemagglutinin protein (HA) from the 1918 virus provide the first clues as to why this virus was so deadly.

\section{“...international support to countries attempting eradication measures is simply prudent."}

In the first stages of infection, $\mathrm{HA}$ is required for viral receptor binding and membrane fusion. The studies showed that the 1918 HA is very avian in struc-

Yoshihiro Kawaoka feels that the current avian flu epidemic requires international action. onwards," but in 1918 people didn't even know that viruses caused influenza, and so there is no information on viruses before that time. And it is difficult to obtain intact viral samples from that long ago.

To obtain information on the 1918 viral evolution, "Ideally," Wilson says, "you would want to dig up a body of someone ture but appears to be able to bind both avian and human receptors.

Asked about the likely transmission route of the 1918 virus, Ian Wilson, of the Scripps Institute, and senior author of Stevens et al. (1), told the JCI that we have "no idea whether the 1918 virus crossed directly to humans from birds or went through an [intermediary] host."

According to Wilson, it is very "difficult to go back to try and determine what changed this virus from the original to make it so deadly. You can see and compare [the 1918 virus] to viruses from the 1930s

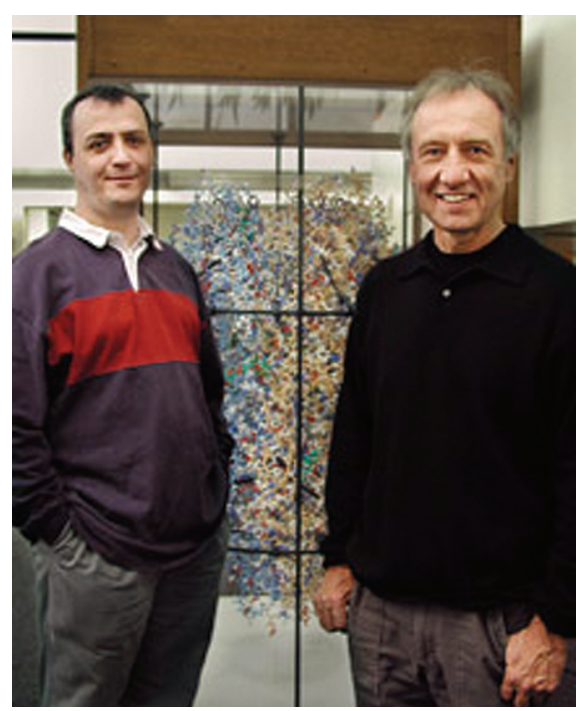

Ian Wilson (right) and James Stevens provide clues into the 1918 viral pandemic. infected prior to 1918." Comparing that virus to the 1918 viral samples and to later isolates could provide another piece of the puzzle of how a virus becomes able to infect a new species and then able to transfer easily within that species, making it a potential pandemic source.

Wilson explains that knowing the key proteins for such infectivity can "give you an idea of what is required for vaccinations. It can tell you when a virus is likely to be different enough that a new vaccine is required." Such work can also indicate target proteins for developing antiviral agents.

Kawaoka agrees that these analyses are indeed essential for combating influenza and other viruses. But he feels that "what is important right now is to eradicate the virus from Asia." Kawaoka adds that "this virus is an international health threat, and international support to countries attempting eradication measures is simply prudent."

\section{Laurie Goodman, New York}

1. Stevens, J., et al. 2004. Structure of the uncleaved human H1 hemagglutinin from the extinct 1918 influenza virus. Science. doi:10.1126/science.1093373.

2. Gamblin, S.J., et al. 2004. The structure and receptorbinding properties of the 1918 influenza hemagglutinin. Science. doi:10.1126/science.1093155. 